\title{
Transformaciones en la construcción de la identidad de las deportistas españolas. Entrenamiento, alimentación y corporalidad*
}

\author{
José Manuel Parrilla-Fernández \\ Sandra Sánchez-Sánchez \\ Universidad de Oviedo. Departamento de Sociología \\ jmparril@uniovi.es; sanchezsandra.uo@uniovi.es
}

Recepción: 14-12-2015

Aceptación: 14-11-2016

\section{Resumen}

El propósito de este artículo es aportar una aproximación comprensiva acerca de las prácticas deportivas, alimentarias y corporales en el deporte femenino en España desde los años cuarenta hasta principios del siglo XXI. El objetivo principal consiste en mostrar de qué modo se ha desarrollado la interrelación entre estas prácticas, así como examinar el proceso sociohistórico de la construcción de los cuerpos de las mujeres deportistas. La metodología utilizada es cualitativa, en particular la entrevista en profundidad semiestructurada de final abierto. La muestra está basada en dos criterios: 1) criterio cronológico, mediante el cual se diferencian cuatro periodos de práctica deportiva competitiva, y 2) criterio de actividad deportiva competitiva, escogiendo a mujeres que han competido a nivel nacional y/o internacional. Los principales resultados evidencian el desarrollo de una interrelación entre los fenómenos del deporte, la alimentación y el cuerpo, de modo que los dos primeros se convierten en modos de construcción del cuerpo en función del rendimiento deportivo.

Palabras clave: mujeres deportistas; entrenamiento físico; alimentación; cuerpo; identidad; técnicas corporales

* Este artículo se enmarca dentro del Grupo de Investigación en Sociología de la Alimentación de la Universidad de Oviedo al que pertenecen los autores y está financiado por el proyecto «Mujeres, Deporte y Dictadura (1939-1975)» del Programa I+D+I 2013-2016 (HAR2013-43652-R). Sandra Sánchez Sánchez es becaria del Programa de Formación del Profesorado Universitario (FPU) del Ministerio de Educación, Cultura y Deporte del Gobierno de España adjudicada en la convocatoria 2012 (AP2012-3993). 
Abstract. Identity transformations among Spanish female athletes: Training, food and corporality

This study analyzes sport, food and body practices among elite female athletes in Spain from the 1940s to the early 2000s. The main aim is, firstly, to show how the interrelation of these practices has developed and, secondly, to examine the socio-historic process of female athletes' body constructions. A qualitative methodology consisting of semi-structured, open-ended interviews was used. The sample was designed taking into account two features of the respondents: 1) a chronological feature in which the sample was divided into four competitive sport periods and 2) a competitive sport feature in which female athletes who have participated in national or international sports competitions were interviewed. The main results reveal the interrelationship between sport, food and body practices. The results also indicate that sport and food practices have become main drivers of the construction of the body aimed towards higher performance in sports.

Keywords: female athletes; physical training; food; body; identity; body techniques

\section{Sumario}

1. Introducción 5. Construcción socio-histórica de

2. Estado de la cuestión la identidad de las deportistas españolas mediante el entrenamiento,

3. Marco teórico la alimentación y la corporalidad

4. Metodología

6. Discusión y conclusiones

Referencias bibliográficas

\section{Introducción}

El deporte se ha desarrollado y se ha convertido en una parte muy importante y definidora de las sociedades contemporáneas, de tal modo que no es solo un fenómeno social más, sino que «lo inunda todo» y va más allá de hábitos, comportamientos o estilos de vida (García Ferrando, 2006; Moscoso Sánchez, 2005: 79). Sin embargo, diversos analistas han observado que existen diferencias de género e incluso discriminación en torno a la práctica deportiva, dado que el deporte es un fenómeno, como otros, donde el género es construido socialmente. Dicha producción se observa en las prácticas deportivas que son consideradas masculinas o femeninas y en los valores asociados al género, donde la lucha y la fuerza siguen manteniéndose como características masculinas, además de las formas fisiológicas, en las que el cuerpo musculado es propio y único del género masculino (Theberge, 2012; Hall, 1996; Girela Rejón, 1996; Camacho-Miñano, 2013; Muñoz González et al., 2013; Espeitx, 2006, Smith, 2010). Es necesario realizar un estudio del desarrollo sociohistórico de la práctica deportiva de élite de mujeres para observar los cambios que se han dado en la misma, tanto en el deporte específicamente como en la construcción 
de sus cuerpos y el cambio del uso instrumental de la alimentación en relación con la actividad física competitiva. Los enfoques científicos aplicados a las relaciones entre el cuerpo, la nutrición y el deporte se centran en realidades de grupos específicos o bien en fases temporales muy concretas. En este sentido, se trata de trabajos sesgados, porque no analizan empíricamente los procesos sociohistóricos en los que se enmarcan las prácticas y las conductas de los sujetos de estudio, ni el modo como el cambio de dichas prácticas y de dichas conductas influyen en la construcción social del cuerpo. Esa es la aportación que pretende ofrecer el presente artículo a través del estudio de generaciones de mujeres deportistas de élite.

El objetivo consiste en ofrecer una nueva visión del cambio sociohistórico de dichos fenómenos interrelacionados en mujeres deportistas desde la década de 1940 hasta los primeros años del siglo XXI. El estudio busca comprender cómo los fenómenos se van imbricando con el cambio paulatino hasta convertirse en una misma realidad vital para los deportistas. El propósito de este artículo consiste en comprender de qué modo ha cambiado la interrelación entre las prácticas deportivas, alimentarias y corporales dentro del deporte femenino en España. De este propósito se desprenden dos objetivos: 1) investigar la construcción social del cuerpo de las mujeres en relación con las prácticas alimentarias y deportivas, y 2) la manera que tienen las mujeres de desarrollar su identidad a través de los diferentes ideales femeninos existentes y cambiantes desde los años cuarenta hasta principios del siglo XXI. Las experiencias narradas por las mujeres deportistas permiten observar las diferencias y las razones que tienen para construir sus cuerpos, así como ver las técnicas que utilizan para controlar el peso o alcanzar el máximo rendimiento deportivo. También se puede observar cómo se perciben a sí mismas y si el ideal de mujer prevaleciente en cada época está cerca o lejos del ideal de deportista de élite. La hipótesis inicial sugiere que, a lo largo de los años estudiados, la especialización, dentro del ámbito deportivo, conlleva cambios en las prácticas deportivas y alimentarias que modificarán los patrones y las percepciones corporales en las mujeres deportistas.

\section{Estado de la cuestión}

En España, a pesar del desarrollo y de la democratización del deporte (Moscoso et al., 2014), la situación de la mujer ha mantenido los estereotipos hegemónicos asociados al género (Puig Barata y Soler Prat, 2004). La España franquista impuso un modelo de deporte y de educación física en función del sexo, a través no solo de técnicos sino también de médicos, asesores religiosos y políticos, que, en el caso de las mujeres, iba dirigido hacia la maternidad y el cuidado de la familia. En este sentido, los deportes se dispusieron en torno al sexo, de modo que se diferenciaban en espacios masculinos y femeninos. Las mujeres tenían un difícil acceso a la actividad física y una marcada disciplina de género como forma de adoctrinamiento y control de las voluntades femeninas a favor de la ideología del régimen franquista. La representación 
dominante de la mujer en el deporte propendía a resaltar los valores estéticos frente a los valores relacionados con lo masculino, como la fuerza; además, no eran consideradas profesionales y realizaban deporte en una época de escasez alimentaria (Manrique Arribas et al., 2009; Gil Gascón y Cabeza Deogracias, 2012; Pujadas et al., 2012, 2016).

Si bien en los años del franquismo la mujer solo podía realizar actividad física "femenina» y era alejada del deporte "masculino» por excelencia, el fútbol, además, debía cuidar su modo de mostrar el cuerpo como comprensión de decoro (Gil Gascón y Cabeza Deogracias, 2012). En el desarrollo del deporte a principios del siglo XXI se siguen observando estos dos mundos, el femenino y el masculino, donde predominan deportes específicos para cada género. Sin embargo, hay una diferenciación mayor: mientras que los hombres muestran una mayor predilección por el deporte tradicional de competición y que está federado, las mujeres son más propensas a practicar actividades deportivas no regladas y con nuevos significados adscritos en relación con la salud o la estética (Puig Barata y Soler Prat, 2004; Instituto de la Mujer, 2006). Una de las razones para que la mujer tenga dificultades para acceder a la actividad física de alta competición es que la imagen estética hegemónica femenina sigue alejada del cuerpo musculado de los deportistas, lo que provoca que las chicas jóvenes se sientan poco femeninas construyendo sus cuerpos en función del rendimiento deportivo (Camacho-Miñano, 2013). Las actividades físicas y los deportes reservados tradicionalmente a los hombres generan una anomia sobre sus cuerpos respecto del ideal estético hegemónico de mujer, lo que les convierte en «extraños» y en un estigma de la desviación femenina de los cánones estéticos establecidos (Muñoz González et al., 2013).

Esta valoración del cuerpo en relación con el deporte se muestra en la producción científico-social. Por un lado, existen trabajos que relacionan la nutrición, la actividad física competitiva y el cuerpo manteniendo el foco de atención en los desórdenes alimentarios y la obesidad en diferentes grupos sociales como los problemas de salud de las sociedades modernas (Williamson, et al., 1995; Byrne y McLean, 2001; Krentz y Warschburger, 2011; Li y Hooker, 2010; Duncan et al., 2008; Jaime et al., 2011; Navalpotro et al., 2012). Por otro lado, hay trabajos que aúnan los fenómenos del deporte, la alimentación y el cuerpo desde una perspectiva micro, en los que se estudian las narrativas de los sujetos de estudio, la construcción de la identidad a través del cuerpo como un medio de creación de subjetividades y en el que los ideales hegemónicos de género siguen cumpliendo una función normativa (Bridel y Rail, 2007; Busanich, et al., 2014, 2012; Waldron y Krane, 2005; Cosh et al., 2012; Atkinson, 2011). Por lo tanto, el uso del cuerpo sigue siendo un indicador principal a estudiar en mujeres deportistas, puesto que el deporte de rendimiento lo modifica físicamente y ellas participarán en él de acuerdo con la forma en la que se creen esas subjetividades. Incluso, en algunos casos, sus actuaciones llevarán a trastornos o a desórdenes alimentarios.

El desarrollo de la actividad física competitiva en las sociedades modernas ha creado nuevas formas de comprensión del cuerpo. Las interrelaciones entre 
la alimentación, el deporte y la salud como factores generadores de estilos de vida saludables han generado un discurso hegemónico en los comportamientos individuales y sociales a favor de la búsqueda del bienestar individual y social. $\mathrm{Al}$ cuerpo se le imponen todo tipo de conductas que favorecen, al menos supuestamente, la salud, y que lo dirigen hacia el fin de una especie de idealidad saludable, que no solo conlleva la idea de la no enfermedad, sino que también concibe el cuerpo saludable como la base del bienestar de los individuos (Vigarello, 2006). Dentro de las prácticas entendidas como saludables, el deporte y el control de la dieta son dos pilares fundamentales en nuestros días. Así, la atención sobre el cuerpo, incluyendo la dieta y el ejercicio, se ha convertido en una preocupación más y parte de la vida social y personal de los individuos (Petersen y Lupton, 2000).

Como consecuencia, la alimentación, en relación con el cuerpo y la preocupación por la salud, se ha medicalizado y los discursos nutricionales científicos han cobrado tanta fuerza a la hora de dirigir el control social físico que es difícil advertir el intenso componente social que tienen (Lupton, 1996, 2003). La medicalización de la nutrición, trasladada al ámbito de los expertos y de la nutrición, relaciona la obesidad con los hábitos alimentarios y la dieta adecuada. Ello aparece relacionado con el prestigio social que representan los cuerpos sanos y atléticos, dado que la concepción del deporte está directamente relacionada con la noción de un físico ideal «bello y sano», que está controlado y del que se ha eliminado el exceso de grasa y la flacidez en los músculos. Por el contrario, un cuerpo obeso significa falta de control, fealdad, y se convierte en símbolo de falta de salud (Lupton, 1995).

Por ello, ambas prácticas, deporte y control de la dieta, han adquirido una importancia creciente en la construcción del cuerpo en las últimas décadas del siglo XX. Tal y como muestra Fischler (1995: 297 y 303), a partir de esta época, aparece un descenso en el umbral de la obesidad, de modo que se determina que el cuerpo muestra sobrepeso u obesidad con menos peso y volumen que en otras épocas. Además, dado que este tipo de cuerpo no está legitimado simbólicamente, aumenta la lipofobia, es decir, el rechazo a la grasa (Fischler, 1995: 297 y 303; Bourdieu, 1986).

\section{Marco teórico}

El deporte, como fenómeno social, no está al margen de otros fenómenos colectivos, como los relacionados con el cuerpo y la alimentación. Para Bourdieu el deporte es un universo abierto, es decir, una realidad social que no es autónoma, sino que mantiene interrelaciones y comparte estructuras con el sistema social total. Según este autor, «no se pueden estudiar los consumos deportivos [...] independientemente de los consumos alimentarios o de los consumos del ocio en general» (2000: 176). Por tanto, de esta realidad social, se analizará la dimensión del deporte junto con la dimensión alimentaria y la del cuerpo, porque en los deportistas tampoco serán realidades separadas. 
Son relevantes para este trabajo las investigaciones internacionales, tanto teóricas como empíricas, que se enmarcan dentro de la sociología del cuerpo para el estudio de la relación entre el deporte, la alimentación y la forma física (Turner, 2008; Shilling, 2003, 2005; Csordas, 1994; Leder, 1990; Crossley, 2001a; 2001b). Estos trabajos ponen de relieve la importancia de los cuerpos como un objeto de estudio. En particular, dentro del ámbito deportivo, son producidos socialmente junto con los discursos morales y normativos que los acompañan, con lo que se crean cuerpos "normales» $\mathrm{y}$ "anormales», tanto para la sociedad en general como dentro de la dimensión deportiva (Cole, 2000: 440).

Dentro de las investigaciones empíricas se pueden encontrar aquellas que están en relación con las disciplinas corporales que tratan el estudio del cuerpo como instrumento de adquisición de conocimientos dentro de disciplinas físicas. Uno de ellos es el trabajo de Lande (2007) sobre el cuerpo de los soldados y el aprendizaje de la respiración en las actividades de correr y disparar. Otro es el trabajo de Aalten (2007), en el que el foco de atención se centra en las actitudes de las bailarinas frente a las lesiones y el dolor que provocan. Finalmente, el concepto de dolor también ha sido estudiado por Faure y García (2002) dentro del hip-hop. Dichos autores detectan que sus practicantes tienen un autocontrol del cuerpo en función de la perfección de la técnica de baile, donde el dolor se queda en un segundo plano como algo normalizado.

\subsection{Los conceptos de "habitus» y de "domesticación"}

Para analizar los conocimientos corporales, es importante trabajar el concepto de habitus, definido y desarrollado por diferentes autores. Mauss (1971: 340) utiliza el término para explicar dentro del ámbito de lo social la educación de técnicas adquiridas en el cuerpo que funciona como instrumento. Tanto Bourdieu (1986, 1999) como su discípulo Wacquant (2016) recogen este mismo concepto. Para Bourdieu, el habitus consiste en disposiciones incorporadas a través de múltiples experiencias que funcionan como esquemas perceptivos $\mathrm{y}$ que permiten la acción sin racionalización o "cálculo racional de los medios» (1999: 183). Wacquant (2016: 65) explica, continuando el concepto de Bourdieu, que el habitus es el lugar donde las estructuras sociosimbólicas de la sociedad se incorporan en las personas como disposiciones hacia formas de pensar, sentir y actuar, pero también como capacidades entrenadas. Este mismo autor incorporó dicho concepto a sus investigaciones sobre boxeadores, explicando que se puede hablar de un habitus pugilístico, que consiste en las disposiciones mentales y corporales que definen la naturaleza físico-social del boxeador, que se va construyendo a través de la rutina deportiva (Wacquant, 2004: 16, 99).

El cuerpo es «social» en la medida en que representa el lugar de los individuos en la sociedad, dado que la forma corporal y las prácticas producidas y derivadas por el cuerpo representan la clase social de los individuos y, en este sentido, también los grupos sociales a los que puedan pertenecer. Además, tiene un componente simbólico, porque las formas y las características fisiológicas del cuerpo - y de la personalidad — son valoradas según aquello que representan 
(Bourdieu, 1986). De este modo, los significados adscritos simbólicamente al cuerpo adoptarán una forma particular para los deportistas según se constituya la idea de cómo debe ser un deportista, tanto desde el punto de vista fisiológico como psicológico.

Siguiendo este análisis teórico, Bourdieu concluye diciendo que «la disciplina corporal es el instrumento por excelencia de toda especie de "domesticación"» (2000: 182-183). Por tanto, habrá aspectos del cambio social en el deporte que no se comprenderán si no se analiza cómo cambia la disciplina corporal a lo largo del tiempo.

Para observar de qué modo cambian en las mujeres deportistas los patrones de comportamiento y las prácticas deportivas y alimentarias ligados a la disciplina corporal, se complementa el análisis del concepto de domesticación de Bourdieu con el concepto de cuerpo dócil de Foucault. Para este autor, el cuerpo es central en la sociedad como objeto y blanco de poder, porque el cuerpo es manipulado, es educado para obedecer, se vuelve hábil y se le da forma. Foucault aplica al cuerpo el concepto de docilidad, que significa que un cuerpo no es solo un objeto que se puede analizar, tanto en su conjunto como en sus partes, sino que también se puede manipular. Así pues, «la disciplina fabrica cuerpos sometidos y ejercitados, cuerpos "dóciles". La disciplina aumenta las fuerzas del cuerpo (en términos económicos de utilidad) y disminuye esas mismas fuerzas (en términos políticos de obediencia)» (2002: 133 y 135). En ese sentido, el cuerpo dócil se hace manipulable con el objetivo de conseguir un mayor rendimiento a la vez que resulta capaz de obedecer a las normas sociales impuestas. Esto es, el cuerpo se construye en función de la utilidad y del control social, aspectos que dependerán del lugar social del individuo.

Este concepto de domesticación se relaciona con los dos procesos que Foucault ha mencionado en sus trabajos. Por un lado, la anatomopolítica del cuerpo humano, que consiste en la integración de sistemas de control en los cuerpos a través de las disciplinas. Por otro lado, los controles de los procesos biológicos a través de intervenciones y controles reguladores, lo que este autor llama biopolítica de la población (Foucault, 1991: 168). Dentro de la sociología del cuerpo y del deporte está bastante establecida la perspectiva foucaultiana para explicar la evidencia del control y de la disciplina en la actividad física competitiva y cómo afecta al cuerpo (Jarvie, 2006). En particular, se puede mencionar el compendio de trabajos de Markula y Pringle (2006) basados en el ejercicio de la disciplina en el deporte, la construcción de cuerpos con género y de cuerpos en forma y saludables o las éticas del autocuidado.

\subsection{El «cuerpo dócil» y las "técnicas corporales»}

Tanto el conocimiento mimético establecido por la disciplina corporal, explicada por Foucault, como la presentación del cuerpo como forma de representación de los individuos, para Bourdieu pueden ser analizados dentro del concepto de técnicas corporales de Mauss. El cuerpo es el instrumento primordial con el que se conoce y se aprehende la realidad, dado que es capaz de adquirir las 
técnicas corporales de su lugar sociocultural, y las técnicas aprendidas varían en función del grupo social en el que estén inmersos los individuos (Mauss, 1971: 340). Una de las técnicas corporales que Mauss presenta es la que se refiere a las «técnicas corporales en relación con su rendimiento», que son aquellas que tienen que ver con el rendimiento humano y con el adiestramiento, esto es, la adquisición de habilidades (Mauss, 1971: 345 y 353). Se trata de técnicas corporales que permiten la adaptación y la «domesticación» del cuerpo para un fin. El deporte tiene sus propias técnicas corporales de rendimiento (correr o nadar, por ejemplo) que requieren un adiestramiento y una adaptación para el cuerpo del deportista, y es posible que varíen a lo largo del tiempo, por ejemplo, con la especialización propia del desarrollo de la institución deportiva. Para Mauss, estas técnicas son interiorizadas mediante el cuerpo de modo holístico, puesto que el hombre es categorizado como hombre total, cuyas propiedades son biológicas, psicológicas y sociales, y estas son irreductibles, inseparables e interdependientes (Mauss, 1971: 343). Las tres propiedades actúan simultáneamente en el proceso de aprendizaje y reproducción de las técnicas corporales del rendimiento humano. Dado que, como se mencionó arriba, el deporte no puede ser estudiado al margen de otros fenómenos como la alimentación, esta puede ser comprendida como una técnica corporal en función del rendimiento.

\subsection{La conjunción de los conceptos de "habitus» $y$ "técnicas corporales»}

Partiendo de los conceptos de habitus de Boudieu y de técnicas corporales de Mauss, Crossley (2001a, 2001b), con perspectiva fenomenológica, constata en primer lugar que los agentes generan habitus con sus propias acciones, haciendo de los individuos agentes encarnados en los que las disposiciones son incorporadas a través del cuerpo. De este modo, ciertas acciones son interiorizadas y realizadas automáticamente por los individuos, como las formas de andar o de comer, pero han sido adquiridas en ciertos contextos socioculturales que cambian a lo largo del tiempo. En segundo lugar, esa incorporación y automatización de ciertas formas de comportamiento corporal es realizada a través de las técnicas corporales, entendidas como hechos sociales en los que interiorizamos ciertos comportamientos y actitudes. Crossley (2005) aporta también una diferenciación entre las técnicas corporales y las técnicas corporales reflexivas. Las primeras consisten en la adquisición de habilidades, y las segundas, en habilidades para modificar o atender a nuestros cuerpos. Ambas las podemos encontrar en las disciplinas deportivas, pues si, por un lado, tienen sus propias técnicas que deben ser aprendidas con el cuerpo, por el otro, también incluyen técnicas de cuidado y modificación del cuerpo, como realizar ciertos ejercicios para la musculación o la práctica de dietas de adelgazamiento.

La modificación y la adaptabilidad del cuerpo, en definitiva, la construcción corporal, aparecen por medio de dos prácticas que cobran cada vez más importancia a partir de la segunda mitad del siglo XX y que pueden ser entendidas como técnicas corporales. Por un lado, la realización de ejercicio físico para modificar y controlar el cuerpo; por otro lado, se construye el cuerpo por medio de la 
racionalización de la ingesta alimentaria, ambas prácticas dirigidas a la búsqueda de la imagen saludable y bella del cuerpo (Espeitx, 2005, 2006; Smith, 2010).

En España, una práctica deportiva particular - las gimnasias de la formaha sido analizada desde dos modelos fundamentales. Por una parte, mediante un modelo instrumental, que busca un cuerpo enérgico en el que aparece la voluntad de actuar sobre uno mismo, así como la eficacia y el éxito personal. Por otra parte, mediante un modelo relacional, cuya relevancia estriba en la socialización y mantiene una estructura lúdica. Estos dos modelos están actuando hoy en día en la comprensión del deporte (Buñuel Heras, 1994: 114).

\subsection{Prácticas y patrones de comportamiento desde una perspectiva sociohistórica}

Para completar el marco teórico, es necesario señalar que tanto los habitus como las técnicas corporales adquiridas se constituyen y se desarrollan dentro de contextos sociales y culturales, además de cambiar a lo largo del tiempo. Si bien los conceptos vistos hasta ahora permiten analizar las prácticas y los patrones de comportamiento instaurados en el cuerpo, no ofrecen modelos teóricos que ayuden a estudiar y a comprender el cambio social en un largo proceso histórico. Para ello es apropiado recurrir a la sociología figurativa de Elias (1987) y utilizada por Mennell (1996), desde la que se comprende la sociedad como un proceso relacional de individuos interdependientes a lo largo del tiempo.

Elias rompe con la dicotomía entre individuo y sociedad, concepto que no expresa la verdadera naturaleza de la sociedad. Los individuos no son estáticos e independientes, sino seres interdependientes inmersos en un proceso histórico, el proceso civilizatorio, que tiene dos dimensiones fundamentales inseparables e irreductibles: la sociogénesis y la psicogénesis. La sociogénesis consiste en la creación de estructuras sociales, mientras que la psicogénesis consiste en la creación de estructuras de la personalidad. Lo que muestra el proceso civilizatorio es que ambas dimensiones son parte del mismo proceso y que las estructuras de la personalidad fruto de la psicogénesis emergen del propio devenir de la sociogénesis de las sociedades. Los principales análisis en sociología histórica de Elias y Mennell sugieren que todas las sociedades evolucionan desde patrones de comportamiento menos escrupulosos y normativos hacia otros más normativos e interiorizados. Esta evolución se genera en todos los ámbitos sociales, entre ellos el deporte, la alimentación y la salud (Elias, 1987, 1992; Mennell, 1996).

La relación entre la sociogénesis y la psicogénesis, como dos caras del proceso social, tienen el punto de unión en el cuerpo. Muchos de los fenómenos del proceso civilizatorio - la alimentación, el deporte, la guerra, la medicinatienen el cuerpo de los individuos como lugar nuclear de incorporación de las técnicas corporales y las formas de percepción de clase o de grupo. El control social de los individuos, fruto de la sociogénesis, hace que la persona viva ese control en el cuerpo. Recibe y reproduce, fruto de su psicogénesis, los comportamientos corporales que puede y no puede realizar, según su contexto social, según su clase, su origen y/o su grupo, de modo que el cuerpo se vuelve «dócil» en la medida en que el individuo interioriza esos patrones de comportamiento. 
Si el proceso civilizatorio ha afectado al deporte, también ha afectado a la alimentación, lo que ha generado una civilización del apetito que crea conexiones «entre el autocontrol sobre el apetito, la delgadez, la salud y el sexappeal» (Mennell, 1996: 39). Esto hace que la construcción del cuerpo sea también parte de ese mismo proceso civilizatorio desde los diferentes ámbitos de la sociedad. Es decir, la construcción del cuerpo no es solo social, sino también histórica. De este modo, los patrones de comportamiento y las estructuras de la personalidad interiorizados pueden ser analizados mediante los conceptos de técnicas corporales y cuerpo dócil, entendiendo estos desde un enfoque histórico, por lo que cambiarán en cada época dentro del proceso civilizatorio.

\section{Metodología}

La metodología utilizada en esta investigación es cualitativa. En particular, se ha utilizado la investigación cualitativa longitudinal (ILC), que permite descubrir y comprender procesos de cambio a lo largo del tiempo. El uso de la ILC es adecuado para analizar procedimientos temporales extensos en los que el elemento temporal es central, tanto en el diseño del modelo de investigación como en el análisis de los datos que se obtengan. Siguiendo el enfoque de Caïs, Folguera y Formoso (2014), este tipo de enfoque metodológico tiene que cumplir tres características:

1. La pregunta de investigación longitudinal tiene que tener en cuenta el tiempo y versar sobre relaciones causales y de desarrollo.

2. Los datos recolectados se refieren a periodos de tiempo diferentes y comparables entre sí para señalar continuidades o cambios.

3. El análisis de datos debe tener una referencia explícita al cambio a lo largo del tiempo.

Ello permite definir el carácter de las diferentes generaciones y observar los procesos de reproducción y de cambio intergeneracional.

La técnica utilizada ha sido la entrevista semiestructurada de final abierto (Hammer y Wildavsky, 1990), con la cual se realizan preguntas de acuerdo con los objetivos del proyecto. El modo de enunciación o el orden pueden variar en función del transcurso de la entrevista. La finalidad consiste en recabar en profundidad las experiencias vitales, en este caso de mujeres deportistas. Este tipo de técnica permite adentrarse en los sujetos de estudio desde sus experiencias, sus valoraciones y sus prejuicios mediante el análisis de su propio discurso. De ese modo se favorece que sean las deportistas las que generen las categorías de análisis a través de las que se examinarán los resultados.

El diseño de la muestra, disponible en el anexo I, se ha guiado por dos criterios principales:

1. Un criterio primario de carácter cronológico (época de práctica deportiva): «Periodo I», que abarca las décadas de 1940 y 1950; «Periodo II», las déca- 
das de 1960 y 1970; «Periodo III», las décadas de 1980 y 1990; «Periodo IV», desde el año 2000 hasta el tiempo actual. La muestra está compuesta por tres deportistas de cada período.

2. Un criterio secundario, vinculado al nivel de actividad y a la competición deportiva: participación en disciplinas diversas y en competiciones nacionales y/o internacionales.

El criterio generacional se justifica tanto por la diversidad inherente a la edad de las deportistas y a su punto de vista, más o menos alejado en el tiempo y desde el que hablan de su experiencia, como por el diferente contexto histórico-social en el que desempeñan su actividad deportiva. Así, partiendo de la circunstancia de que los primeros testimonios actualmente accesibles deportistas de más edad que aún viven y cuyo estado de salud permite realizar con éxito la entrevista de investigación - inician o desarrollan su actividad deportiva en la década de 1940, se ha establecido como primera etapa la que comprende esa década y la posterior, es decir, los años cuarenta y cincuenta. Dicha época se corresponde con un tiempo de posguerra en España que estuvo marcado por la escasez económica y el bajo desarrollo educativo y deportivo, entre otras carencias significativas. Además, se crearon algunas iniciativas para el encuadramiento de la mujer en el marco del régimen autoritario de Franco que tuvieron una importante repercusión en el acceso de las jóvenes a la actividad deportiva.

Las décadas de los sesenta y de los setenta corresponden a una etapa bien diferenciada en la literatura sobre el franquismo y en la que se lleva a cabo el llamado desarrollismo, que supuso para la sociedad española una notable modernización económica y educativa —aunque en un contexto político no democrático- - así como un impulso a la actividad deportiva y a la educación física de la población. En aras de la simplificación, se ha incluido en este período toda la década de los setenta, en que la extinción del régimen de Franco da paso a la iniciación de un régimen democrático, cuyas potencialidades se desarrollarán en las décadas siguientes.

Un tercer período abarca las dos décadas finales del siglo XX, tiempo en que la democratización política y la modernización de la sociedad española favorecen tanto la extensión de la educación como la participación deportiva de la población, así como el desarrollo de nuevas mentalidades respecto al papel de la actividad física competitiva en el cuidado de la salud.

El cuarto período responde al interés por incorporar en la investigación a las deportistas del tiempo actual y más reciente, en las que se ha incluido a las que desarrollan principalmente su actividad desde el inicio del nuevo siglo hasta nuestros días, para poder observar las transformaciones que se están produciendo en la visión de las deportistas sobre la propia actividad competitiva y su relación con la salud y la corporalidad.

En cuanto al criterio secundario, se ha buscado la representación en la muestra de practicantes de diversas disciplinas deportivas, tanto individuales como de equipo, dentro de las posibilidades para cada categoría cronológica, 
y teniendo en cuenta la diferente implicación competitiva accesible en las diferentes etapas consideradas.

Las entrevistas fueron codificadas mediante el software MAXQDA 10. Para clasificar los datos cualitativos, se realizó una clasificación temática mediante la construcción de códigos de análisis con sus correspondientes subcódigos. Los códigos de análisis emergen del propio discurso de las deportistas y han sido creados a partir de la lectura detallada de las entrevistas.

Posteriormente a la decisión de los códigos de análisis y a la codificación de las entrevistas, se realizó un análisis temático sobre los textos en los que las mujeres expresaban sus experiencias acerca de la práctica deportiva y sus patrones de comportamiento alimentario, así como la relación y la autopercepción sobre sus cuerpos. En primer lugar, se compararon las experiencias de las deportistas de la misma generación y, posteriormente, se analizaron los cambios acontecidos cronológicamente por generaciones. La finalidad del análisis consiste en reconocer, dentro del orden semántico de los discursos de las mujeres, cómo se expresan acerca de su cuerpo y de sus experiencias deportivas y alimentarias dentro de su contexto histórico y social (Conde, 2014). Los resultados analizados para este artículo están presentes en los códigos de «Deporte y educación física», "Alimentación» y «Cuerpo» y en sus correspondientes subcódigos, en los que se establecen las subtemáticas principales abordadas en los apartados siguientes.

\section{Construcción socio-histórica de la identidad de las deportistas españolas mediante el entrenamiento, la alimentación y la corporalidad}

\subsection{Desarrollo del deporte desde un enfoque lúdico hacia un enfoque de exigencia deportiva}

Los discursos de las deportistas de la generación más antigua muestran la actividad física como un entretenimiento. A continuación se observa cómo la actividad física practicada tiene un componente fundamentalmente lúdico en el periodo I. Como explica una deportista, el deporte fue su vida, la actividad que se podía permitir realizar como mujer, cuando no podía hacer otra cosa:

[...] Fueron los mejores años de la vida. No teníamos otra cosa que hacer... La escuela echábante cuando ya eras mayor, ya no podíes ir a la escuela, y en la familia pa estudiar todos no había. (Entr.40-50/1. P. 322)

El discurso de los siguientes fragmentos de los periodos I y II muestra que el deporte tiene un significado que se encuentra más cerca de una forma de diversión que de una actividad de rendimiento y que los entrenamientos no estaban pautados. El cuerpo no estaba instrumentalizado en función de la actividad física competitiva que se realizaba. El deporte femenino no tenía el mismo prestigio que el masculino en la época, por lo que la adquisición de técnicas corporales específicas en la práctica deportiva no era una cuestión importante. 
Los entrenamientos hacíamos lo que queríamos... Nadie nos reñía, jugábamos porque queríamos y porque nos gustaba. (Entr.40-50/1. P. 243)

En esta época, la parte lúdico-recreativa del deporte es más importante que la parte competitiva. En el siguiente discurso se observa el rechazo a la competición frente al deporte como una actividad lúdica. Las mujeres que lo practican en estos primeros periodos viven en unos contextos históricos donde en la actividad física competitiva femenina se observa más el valor estético -el pasear en la piragua, por ejemplo, una actividad más adecuada para el estereotipo femenino de la época- que la competición, asociada al mundo masculino:

[...] y a mí me gustaba eso, pasear en la piragua, pero competir no... Bueno a mí competir no me gustó nunca. (Entr.60-70/2. P. 185)

En el periodo III se detecta ya una transición en la dedicación al deporte, de modo que se experimenta un cambio desde el que mostraba un carácter más lúdico hacia el de alto rendimiento. Este proceso es consciente y se refleja en la siguiente comparación, que muestra cómo ellas detectan el cambio. La disciplina y la dedicación al deporte aumentan como parte de la rutina de las deportistas como una parte más de sus vidas:

Bueno, en aquella época, los entrenamientos tenían más aspecto lúdico realmente que... que de rendimiento ¿¿no? Aunque bueno, trabajábamos, entrenábamos todos los días [...] empezabas a las seis y media pues hasta las nueve [...]. (Entr.80-90/1. P. 45)

Sin embargo, se trata de un periodo transitorio, puesto que el siguiente relato explica cómo se van endureciendo los entrenamientos. Empieza a aparecer una construcción de la identidad del deportista en función del entrenamiento. Esas mujeres incorporan e interiorizan el esfuerzo continuado y rutinario hasta normalizarlo. En dicha época ya se puede advertir que aparecen unas disposiciones hacia el entrenamiento extremo que pertenecen al habitus de la deportista:

[...] tantos años con D..., pues psicológicamente tenía lo de la... o sea lo de entrenar todos los días superduro, hacer mogollón de entrenos [...]. (Entr.8090/2. P. 83)

Las deportistas del periodo IV muestran cómo la continua interiorización de la exigencia y la disciplina deportivas ya es plena. El ejercicio físico se convierte en una forma de vida, y la sensación de sufrimiento termina siendo una constante que refuerza su trabajo. La exigencia en el deporte llega a ser una necesidad, porque se ha convertido en una práctica interiorizada física y psicológicamente. Tal y como Wacquant observa, las deportistas adquieren un habitus de deportista que les hace percibir el entrenamiento como una necesidad: 
Yo, para mí, ha sido una forma de vida, hasta el punto que yo he necesitado sentir en mi cuerpo esa exigencia, porque la he necesitado, es así [...]. (Entr.90act/3. P. 231)

En los discursos de estas deportistas se observa que viven por y para el deporte y la competición. Frente a los periodos anteriores, donde el componente lúdico estaba presente en el discurso, ahora este desaparece del relato, y la importancia del discurso está centrada en el entrenamiento, la clasificación y la competición como los elementos principales de la vida de las deportistas:

Es que llega un momento, cuando estás así en este momento, que es que nos queda un mes para el clasificatorio [...]. Y es que vives por y para ello. Estás centrada sola y exclusivamente en ello. Y llego al entreno y nos animamos las dos pensando en ello. Cada salida que hacemos en el entrenamiento decimos «iVenga!», como si fuésemos a competir [...]. (Entr.90-act/1. P. 358)

Tan importante es la competición para las deportistas de este último periodo que los resultados se convierten en una máxima ética para ellas. El habitus no es solo una cuestión fisiológica, sino también sociológica y psicológica. Es necesario el esfuerzo y la consecución del rendimiento como una norma moral, y no solo como un logro deportivo:

[...] Y si esos objetivos se cumplen, pues digamos que tu rendimiento éticamente ha sido bueno. (Entr.90-act/3. P. 110)

\subsection{De la alimentación familiar a la medicalización de la dieta}

Tanto en el periodo I como en el periodo II las deportistas relatan que la nutrición no está relacionada con la práctica deportiva, sino que está unida a la comida familiar. Además, se percibe que la alimentación no era buena para hacer deporte. La privación material acontecida en los años de la posguerra española hace imposible la implantación de modelos nutricionales sofisticados. Igual que Mennell explica que, en el proceso de los cambios alimentarios en relación con el cuerpo — como por ejemplo la aparición de la obesidad-, es necesaria una disponibilidad abundante de alimentos (Mennell, 1996: 38), esta también será necesaria para que se puedan aplicar dietas específicas para deportistas:

[...] en aquellos tiempos el deporte tenía problemas, porque ten en cuenta que la gente tampoco es que estuviera alimentada como están los deportistas de hoy [...]. (Entr.60-70/3N. P. 23)

A partir del periodo III, la alimentación empieza a salir del ámbito familiar y entra dentro del ámbito deportivo. Figuras de entrenadores y de médicos comienzan a hacerse cargo de las recomendaciones alimentarias. Sin embargo, aún hay deportistas que no las siguen del todo y el cambio alimentario 
no siempre es asimilado por las deportistas. Hay un choque entre los gustos y las pautas alimentarias que les imponen. Fundamentalmente, se puede observar que aparece una medicalización de la nutrición dirigida hacia la instrumentalización del cuerpo. La dieta se racionaliza y se ajusta al rendimiento. Se crea un control social sobre los entrenamientos y la alimentación de las deportistas:

[...] X..., un médico [...] le mandaba todas las pautas de entrenamiento y todo lo que tenía que comer [...]. (Entr.80-90/2. P. 119)

[...] me decía X [un médico] que no comiera patatas fritas, porque, con esas piernas, había que bajar esas piernas... Entonces, claro, a mí lo que me gustaba eran las patatas fritas y las hamburguesas... [...] Yo las comía igual. Digo «Yo mañana tengo dos horas, esto lo bajo», es que yo ya era así de constitución [...] Entonces me decía que no comiera, pero yo las comía igual. (Entr.80-90/2. P. 120-125)

Progresivamente se va interiorizando la relación entre la alimentación y los resultados deportivos. La nutrición se empieza a convertir en parte de la disciplina deportiva y se marcan unas pautas a las deportistas, las cuales comienzan a interiorizar los patrones alimentarios en función de la actividad física que practican como una parte más de su rutina y se alejan de otros contextos como el familiar, donde las disposiciones hacia la comida son diferentes:

[...] cuando estás trabajando ya en el alto rendimiento, tú sabes que el sobrepeso puede ser muy perjudicial en muchos aspectos, entonces eso tienes que cuidarlo, ahí sería una inconsciencia, también que no cuidaras la parte de la alimentación cuando realmente practicas un deporte donde de alguna manera te juegas el tipo, te juegas la vida, ¿no?, donde hay acrobacias, donde influye mucho tu... tu condición física, y lo que tú pesas a la hora de realizar los ejercicios. Sería inconsciente que no cuidaras la alimentación. (Entr.80-90/1. P. 85)

Esta interiorización se consolida en el periodo IV, el último estudiado. Aparecen nuevas formas de aprendizaje alimentario. Una de las deportistas reconoce que aprendió a comer con el deporte. La nutrición es una disciplina que se va consolidando en la vida de las chicas que practican una actividad física competitiva como un elemento más del deporte. En el siguiente fragmento se observa que los patrones alimentarios de las deportistas que se han ido consolidando en los periodos anteriores se presentan como parte de su educación desde niñas. Es decir, el proceso sociogenético que se ha seguido de normalización de la dieta se reproduce psicogenéticamente en las mujeres deportistas de la última generación como una parte más de su educación física, obligada también por la exigencia que tiene la actividad física competitiva en la época actual. La nutrición se convierte en un saber específico dentro de su ámbito, en una técnica corporal reflexiva para modificar el cuerpo y mantenerlo de forma adecuada para la práctica deportiva: 
Yo, la verdad, tengo que reconocer que aprendí a comer con la bici. Yo siempre comí muy mal. Pero muy mal, muy mal, muy mal, muy mal. Desde pequeña siempre tuvieron muchos problemas conmigo porque no comía nada. $Y$ a raíz de que en infantiles empecé a salir a campeonatos fuera y igual me pasaba una semana lejos de casa, pues empecé a comer por necesidad [...]. (Entr.90-act/2. P. 49-50)

[...] cuando eres profesional tienes profesionales específicamente de eso, que te ayudan a entender más las cosas, saber por qué hay que comer esto, por qué es mejor esto, por qué... Y como yo siempre he sido bastante disciplinada, siempre me ha gustado ser muy metódica. Digamos en esas cosas... cuidarlo mucho. Sí que he aprendido mucho. (Entr.90-act/3. P. 81)

Finalmente, la alimentación se entiende como una especialización que debe ser dejada en manos de los expertos, de forma que no se convierta en una obsesión de las deportistas. Dentro del control de sus prácticas alimentarias, aparece la figura de un experto médico o de un nutricionista que dirige su alimentación, la cual se convierte en un saber tan específico que ellas aceptan los dictados del médico. El cuerpo se convierte en un objeto de cuidado y las deportistas lo protegen de manera dócil y disciplinada:

También resulta difícil de poder controlarlo todo, y ese control igual te lleva a una obsesión que tampoco es buena. Entonces por eso es importante tener una persona cerca, en la que tú confíes y que esa parcela te la lleve ella. [...] En ese sentido, tienes que depositar toda la confianza en esa persona. En el deporte de élite tiene que ser así. [...] Pero ya cuando tienes un desgaste muy importante, y entrenos, y los domingos..., eso ya sí que tienes, sobre todo en la mujer, temas de hierro, anemias... Todo eso es muy importante. (Entr.90act./3. P. 172-173)

El proceso de especialización nutricional conduce hacia la medicalización de las deportistas con el fin de regular su desgaste corporal, por lo que aparece el uso de suplementación alimentaria considerada legítima, dado que no son productos prohibidos por las instituciones deportivas. Dentro del habitus de las chicas que practican actividad física competitiva no solo se ha inscrito y normalizado el cuidado de la dieta a través de los alimentos, sino también el uso de los complementos nutricionales como una parte más de su condición de deportistas:

[...] La gente sí que... No sé si abusa, pero sí que tira mucho de ese tipo de sustancias. [...] hay muchos entrenadores [...] que sí que recomiendan el uso de vitaminas. Ya no te digo nada raro, pero sí vitaminas y complementos en la dieta, porque al final llevas al cuerpo a un extremo que muchas veces sí que es verdad que, cuando estás en pleno rendimiento y en forma, te encuentras mucho más débil ante cualquier enfermedad, como también ante una bajada de hierro o una simple anemia. (Entr.90-act/2. P. 110-112) 
La medicalización de la dieta se va convirtiendo en una práctica normalizada y por tanto justificada. En algunos casos, la suplementación alimentaria roza el dopaje. Se toman muchas pastillas y medicamentos, y esta práctica se convierte en algo normalizado:

[...] Pero, claro, después de eso sí que tienes montones de cosas que te tienes que tomar. Y que cualquier persona que te vea que sea una persona laica en ello pues diría «iGuau!». Pero es normal, es lo que tienes que hacer. Porque sí que no eres capaz de asimilarlo con tu propio organismo. Incluso yo era una defensora de los recuperadores intravenosos, que antes... Pero para mí, desde mi punto de vista, era mejor. No te tenías que abarrotar de pastillas de lo cual vayas a asimilar mucho menos. $\mathrm{Y}$ al fin y al cabo, si te vas a dopar, te vas a dopar aunque esté prohibido ponerte algo intravenoso. Está claro. (Entr.90act./1. P. 310-313)

\subsection{Del ideal corporal femenino patriarcal al enfoque instrumental}

Las deportistas hablan de sus cuerpos, pero no lo hacen igual en cada época estudiada. Hay una evolución sobre la percepción de sus cuerpos a lo largo de las diferentes generaciones.

En el periodo I la moral de la época no permite que las mujeres enseñen su cuerpo. Como consecuencia, la norma estética de ocultación de este acompaña a la práctica deportiva. Las deportistas presentan en sus relatos el cuerpo a través de su ocultación por medio de la ropa que utilizan. Esto significa que el físico de las mujeres durante el franquismo es principalmente instrumentalizado en función del estereotipo femenino y que, en el caso de ellas, el deporte no está relacionado con la instrumentalización hacia el rendimiento deportivo, sino con un modelo de disciplina y de control social de la mujer:

[...] la falda, del costado le salía encima una faldita para taparte el triángulo... "pecaminoso» [...] mira que escote y que todo [...]. (Entr.40-50/3. P. 22)

Durante el periodo II continúa la ocultación física por medio de la ropa deportiva, aunque en algunos relatos como el siguiente se reconoce que se comienza a descubrir el cuerpo. En un comienzo, la ropa es incómoda y poco adecuada para la práctica deportiva, porque provoca que ellas cometan faltas en el juego, por lo que se comienza a eliminar su exceso. Ello constituye un primer paso hacia la instrumentalización del cuerpo en función del rendimiento, y no de factores exógenos al deporte:

Y la falda plisada era... Tenía que ser por donde la rodilla, pero nosotras enseguida la quitamos. El equipo nuestro, ¡eh! Debimos de ser de las primeras, porque decíamos que, al saltar durante el bloqueo, la falda subía... (Entr.60-70/1. P. 63)

En este periodo el cuerpo femenino continúa cubierto en algunos casos. El habitus de estas mujeres está relacionado con la educación moral de la época 
y con el control social al cual ellas son sometidas. Como no podía ser de otro modo, dicho aspecto se presenta también dentro de la dimensión deportiva. Este control normalizado en las mujeres de la época, donde su cuerpo es regulado a través de la ocultación, conlleva la interiorización de unas formas de comportamiento social que, frente a la exhibición corporal, provocan pudor y contrariedad entre las mujeres:

[...] había mucho complejo [...], yo tenía un amiga, Ch..., que jugaba [...] no se atrevía a salir a jugar con falda corta y sin medias. Se ponía medias, el pololo, la falda y salía con gabardina [...] cuando llegaba a pista hacía ñaca y se la quitaba, la dejaba y se ponía. [...]. Yo pienso que son unos conceptos que se viven, que los llevas tú puestos porque te los han enseñado. (Entr.60$70 / 3$ N. P. 171)

Sin embargo, la misma entrevistada es un ejemplo del proceso de cambio que comienza a emerger en el tardofranquismo. Ella misma nos muestra cómo se enfrenta a otras mujeres de la época rebelándose contra la norma:

[...] yo nunca tuve ningún problema de ninguna clase ni de censura, y eso que había para censurarnos. De vez en cuando, de esas gamberradas que hacíamos, ni de censura ni de nada. Todo lo más que podía pasar era que te llevaras un bikini $[\ldots]$ y que salieran las señoras de los vestuarios y dijeran: «Bikini no», y decías: «¿Ah no? ¿Bikini no?». Y te quitabas la parte de arriba y entonces se organizaba, porque, como había dicho que no, pues te la quitabas, ¿no? Y estábamos solo chicas y se organizaba una [...] (Entr.60-70/3N. P. 11)

En el periodo II comienza otra temática diferente, la que trata sobre la ejercitación del cuerpo del deportista, que se convierte en un cuerpo musculado. Parece que, al finalizar esta época, comienza el paso hacia la preocupación por ese tipo de físico, pero en el periodo II las mujeres no hablan de sí mismas haciendo ejercicios con los que conseguir un cuerpo musculado, sino que eso pertenece a las generaciones que comienzan a practicar deporte después de ellas. Las primeras técnicas corporales que aparecen son las relacionadas con la adquisición de habilidades deportivas y será en los años siguientes cuando aparecerán las técnicas corporales reflexivas para modificar los cuerpos de las mujeres deportistas:

[...] yo creo que fue al final, cuando nosotros lo dejamos ya, cuando lo empezamos a dejar. Yo veía a la gente que entró detrás, pues haciendo mucha musculación, preparándose $p a$ tener más fuerza, $p a$ tener más salto, $p a$ tener ya una preparación física mucho más específica. Nosotras hacíamos, como quien dice, un calentamiento, pero no una preparación para mejorar el salto tal..., sino por calentar [...]. (Entr.60-70/1. P. 241)

Por ello, en el periodo III, los relatos del cuerpo tratan sobre la percepción de la dicotomía entre el físico del deportista, un físico musculado, y otras formas corporales. La transición de habitus exógenos al deporte en relación con 
el estereotipo femenino hacia disposiciones corporales específicas con el fin de alcanzar un mejor rendimiento deportivo constituye un conflicto para las mujeres. Su autopercepción puede conllevar esa concepción anómica y desviada de los estereotipos sociales en otros ámbitos:

Hombre, a veces, digo yo: «ijo! ¡Estas [piernas]...!». Las veía y son... un poco, porque siempre, casi siempre, la gente decía: «jo! ¡Vaya piernas más tal, vaya...!». Y sí que a veces tal, pero luego ya dices tú: «Bueno». Te acostumbras y dices: «jo! Es tu cuerpo, ¿no?». Pues..., pero sí que a veces, yo, [...] y mis piernas seguían igual... Son así... mis cuádriceps. Lo que más eso son los cuádriceps, y son así... y son así. Y llega un momento en que digo yo: «Son así, son así, por eso soy yo así, por eso corro así [...]». (Entr.80-90/2. P. 127)

Dentro de esa dicotomía entre el cuerpo ordinario y el cuerpo del deportista musculado, las mujeres comienzan a decidirse por conseguir el estado físico necesario para llevar a cabo una práctica deportiva excelente. Al igual que en los trabajos de Wacquant, se puede hablar de un habitus de deportista y de unas técnicas corporales reflexivas donde la importancia de la modificación del cuerpo se traslada al rendimiento más que a la representación social del aspecto femenino. Engordar o adelgazar, en definitiva, modificar su físico, ejerce un efecto importante en el rendimiento deportivo. Aquí hay ya un pequeño tránsito hacia la búsqueda personal del peso en función de ese rendimiento deportivo. Comienza el control del cuerpo:

[...] un pelín que engordas ves eso. Se traslada inmediatamente a la cancha. Si tu tienes que saltar 90 para hacer un remate y engordas cuatro kilos, es como saltar con una mochila de cuatro kilos encima, y no vas a saltar. Entonces tu misma tienes que... Ya lo ves, ves que, que no te conviene. Entonces te cuidas. (Entr.80-90/3. P. 193-195)

Cuando las deportistas aceptan su vida deportiva y se identifican con ella, desaparece la dicotomía entre el cuerpo ordinario y el cuerpo ejercitado. Siguiendo este mismo tema sobre el conflicto entre el cuerpo ordinario y el cuerpo ejercitado, la estética física pierde importancia:

Bueno, yo creo que ya cuando estás en el alto rendimiento, ya tus objetivos son otros, y la motivación que te mantiene ahí para..., para el sacrificio diario y tal, ya no tiene nada que ver con ver tu cuerpo de una manera o de otra [...]. (Entr.80-90/1. P. 102-103)

Durante el periodo IV se mantiene la aceptación del cuerpo musculado que muestra un peso acorde con el rendimiento deportivo. El cuerpo se convierte, según sus propias palabras, en un peso forma. Para las deportistas, debe tener unas medidas, un peso y una musculación determinados, conseguidos a partir del entrenamiento y de la alimentación como técnicas corporales reflexivas. El uso de dichas técnicas y la musculación que se va adquiriendo de forma progre- 
siva constituyen una disposición adquirida y autocontrolada por las deportistas como parte de su naturaleza físico-social, de modo que se identifican con sus cuerpos sin contradicciones:

[...] sí que hay momentos en los que igual la gente te dice: «iBuah! ¡Qué fuerte estás!». O que llegas a un bar y te coge el típico tío por el bíceps y le dices: «Te doy envidia, ¿eh?» [risas]. Pero no, a mí nunca me importó. Yo sé que para llegar a ser, para llegar a estar donde estoy, no puedo ser una 90-60-90 y, a parte, tampoco me gustaría serlo. (Entr.90-act/1. P. 108-109)

Los constantes entrenamientos provocan que el cuerpo se vaya adaptando al esfuerzo requerido y que ellas mismas sean conscientes de su adaptación. En definitiva, se dan cuenta de la interiorización de los patrones de comportamiento que adquieren como parte de esa naturaleza deportiva, lo que genera unas conductas propias relacionadas con la disciplina y la domesticación de sus cuerpos. En tal proceso no solo se han adaptado al esfuerzo, sino también al sufrimiento, que, al ser interiorizado por las deportistas, acaba convirtiéndose en una emoción positiva para ellas. El sufrimiento es parte de su habitus:

[...] Al final, la gente que está corriendo en profesionales lleva muchísimos años en esto. Entrenas muchísimas horas y, al final, tienes una adaptación de tu cuerpo al esfuerzo [...]. (Entr.90-act/2. P. 115)

[...] yo he necesitado sentir en mi cuerpo esa exigencia [...] he sufrido mucho entrenando, pero es que ese sufrimiento me hacía sentirme bien [...]. (Entr.90act/3. P. 231)

La instrumentalización del cuerpo es máxima en este último periodo, en el que las técnicas corporales reflexivas, el entrenamiento y la dieta alimentaria para conseguir afinar el cuerpo son tan estrictas que pueden afectar a otros procesos fisiológicos como, por ejemplo, la falta de la menstruación o la regulación de la misma por medio de hormonas:

[...] cuando llegas al final, tienes que afinar al máximo. Eso te hace perder grasa, lo cual también provoca que pierdas tus periodos, o sea, tus ciclos menstruales. Y, vamos, de hecho, es normal que estés los dos últimos meses sin que te baje la regla o que tengas unas reglas muy largas [...]. (Entr.90-act.1. P. 430)

Y hay muchas chicas deportistas que utilizan la píldora anticonceptiva para regular la regla. Juegan con esto los médicos de que te baje la regla [...] que te cuadre el día de la competición [...] cuando tienes ya demostrado en tu persona que es el día que estás más fuerte, o que te pille pues el tercer día de regla o algo así. (Entr.90-act/1. P. 436)

En las deportistas más recientes, el deporte de alto rendimiento aparece tímidamente como una actividad cuestionada como poco saludable, precisamente por la exigencia que provoca que ellas lleven el cuerpo al extremo. 
Sin embargo, dentro de la dimensión deportiva, la instrumentalización del cuerpo, el dolor y la falta de salud se han normalizado como parte de la cultura deportiva:

[...] Yo creo que el deporte de alto rendimiento tampoco creo que sea saludable, porque al final sí que es verdad que llevas al cuerpo a unos extremos [...]. (Entr.90-act/2. P. 148)

\section{Discusión y conclusiones}

El análisis de los resultados de esta investigación se sostiene sobre la interpretación de un proceso en el que los cuerpos de las deportistas van construyéndose socialmente y cambiando de significado a lo largo de los periodos estudiados. Estos periodos evidencian que existe un proceso de cambio desde prácticas deportivas con un enfoque principalmente lúdico hacia prácticas deportivas cada vez más exigentes, tanto desde el punto de vista físico como mental, por lo que se interpreta que esta evolución es un episodio de un proceso a largo plazo como los que han presentado Elias (1987) y Mennell (1996) en sus trabajos.

Como se ha mostrado, en los primeros periodos analizados, el deporte tiene un carácter más lúdico. Conectando con otros trabajos (Gil Gascón y Cabeza Deogracias, 2012), vemos que el físico de las mujeres no está ligado al deporte por medio de técnicas corporales de rendimiento (Mauss, 1971), sino que el centro de atención es su ocultación y su sometimiento a los dictados morales del patriarcado vigente en el franquismo. Por tanto, los cuerpos, ocultos bajo la indumentaria deportiva, no obedecen a una construcción social directamente relacionada con la actividad física competitiva, sino que se vuelven "dóciles» en relación con los valores femeninos y estéticos de aquella época (Foucault, 2002: 133). En este sentido, los cuerpos de las mujeres encarnan socialmente su posición, su identidad y su orden simbólico (Crossley, 1995). Este resultado conecta con otros trabajos históricos sobre mujer y deporte que muestran que el cuidado de la feminidad está relacionado con el destino familiar que se le requiere (Manrique Arribas et al., 2009).

El deporte femenino de estas primeras épocas, cuyo enfoque es lúdico, no tiene relación directa con la alimentación, pues esta queda dentro del ámbito familiar. Por tanto, las conductas y los hábitos nutricionales aún no son tampoco técnicas corporales relacionadas con el rendimiento deportivo ni el cuerpo está "docilizado» en función de este, pues tampoco existe una necesidad de tener un físico de deportista de élite. Sin embargo, en la medida en que se desarrolla el proceso de cambio, al comparar los periodos, se observa una interrelación creciente entre deporte, alimentación y cuerpo. Conceptos como cuerpo dócil y técnica corporal cobran relevancia en el análisis, pues se observa el aumento, a través de los periodos estudiados, de las transformaciones y de las percepciones que estructuran los cuerpos en función de la exigencia deportiva. Así, la actividad deportiva competitiva y los cuerpos «dóciles» de las deportistas evolucionan hacia un significado social de rendimiento. Ese paso hacia una 
mayor exigencia deportiva se interpreta aquí como un avance en el desarrollo de las técnicas corporales de rendimiento en la actividad física competitiva, donde la alimentación cobra cada vez más importancia como parte de ese desarrollo, dado que se impone como una exigencia inexcusable.

En este proceso de cambio se observa un periodo (1980-1999) donde conviven en conflicto los significados anteriores de deporte lúdico con los nuevos significados sobre el alto rendimiento. Algunas mujeres tienen dificultad para entrar en la dinámica de las nuevas técnicas y las nuevas formas de construcción del cuerpo, dado que estas aún no han sido interiorizadas. Las representaciones sociales de los cuerpos de las mujeres tienen componentes simbólicos que enfrentan las características fisiológicas y de la personalidad que conforman a las deportistas con las características de otros tipos de representaciones femeninas existentes en el imaginario de la época (Bourdieu, 1986). Las chicas que practican actividad física competitiva ya no representan simbólicamente esos estereotipos sociales de mujer de otros ámbitos externos al deporte (madre, esposa, pareja sexual), y por ello, en algunos casos, rechazan el cuerpo musculado por lo que este representa para los demás, es decir, no están conformes con ese físico extraño y anómico que se aleja del ideal femenino y se desvía de los patrones corporales hegemónicos (Camacho-Miñano, 2013; Muñoz González et al., 2013). El conflicto tiende a desaparecer en el último periodo estudiado (2000-2014), pues esas mujeres han aceptado la imagen de deportistas de élite y reestructuran su vida, su alimentación y la forma de su cuerpo en función del deporte, como elementos de un todo unificado.

En dicho sentido, las deportistas más recientes modelan su cuerpo en función del peso y de la forma que necesitan para competir, con lo que cobran importancia los conceptos de umbral de la obesidad y lipofobia de Fischler para analizar la práctica alimentaria dentro del ámbito deportivo (1995: 297 y 303). Por un lado, la disciplina nutricional se instrumentaliza y genera un umbral de la obesidad específico dentro de la práctica competitiva de élite, que se ha reducido hasta hacerse muy estricto. Por otro lado, este peso-forma crea una lipofobia particular dentro del ámbito deportivo, definida por el distanciamiento de ese peso-forma determinado.

Finalmente, el proceso analizado a lo largo de cuatro periodos desemboca, en el más reciente, en la cristalización de formas instrumentales de construcción del cuerpo: por un lado, mediante entrenamientos severos y disciplinados, $y$, por otro, mediante un estricto control alimentario. De modo que si, en los primeros periodos, el entrenamiento deportivo y la alimentación aparecen con un significado relacional y socializador, en los periodos más recientes aparecen como formas instrumentales de construir el cuerpo de las deportistas de élite. Siguiendo el enfoque de Mauss (1971: 342), para las deportistas, su cuerpo se ha convertido en su «herramienta principal», por lo que debe ser ejercitada y mejorada continuamente. Esto quiere decir que las exigencias en el entrenamiento y en la nutrición serán comportamientos interiorizados y reproducidos por ellas, que se identificarán con ese modo de vida propio del deporte profesional. Ello nos remite a los modelos relacional e instrumental, mediante los 
que se ha observado cómo el proceso histórico del deporte de competición ha experimentado una transformación en la que la alimentación se ha convertido en un elemento clave, dado que es una de las principales formas de construcción física aptas para la competición de élite (Buñuel Heras, 1994; Espeitx, 2005, 2006). El gráfico 1 expresa dicha evolución de forma sintética.

Gráfico 1. El deporte de competición y la alimentación como formas de construcción social del cuerpo

\section{Modelo relacional de la construcción social del cuerpo}

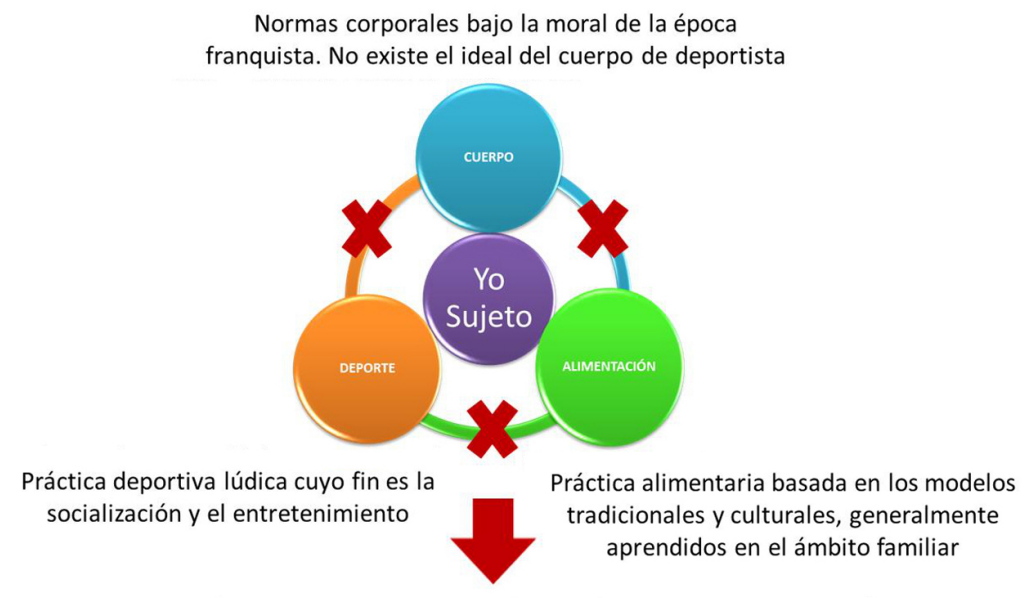

\section{Modelo instrumental de la construcción social del cuerpo}

Cuerpo entrenado para soportar la exigencia deportiva. Concepción del cuerpo como una herramienta para alcanzar las metas deportivas

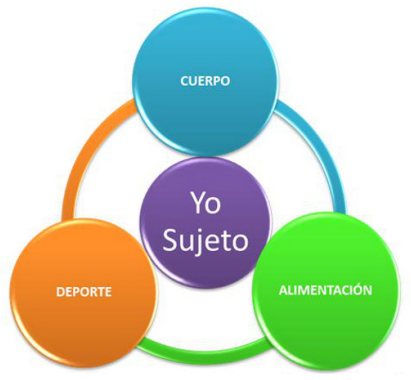

Práctica deportiva cuya finalidad son los logros deportivos y/o el éxito personal
Práctica alimentaria especializada y medicalizada orientada a los logros deportivos

Fuente: elaboración propia. 
El presente trabajo ha analizado el desarrollo y la evolución de la práctica deportiva femenina desde los años cuarenta hasta la década de 2010, en los que se puede observar una evolución en las constricciones sobre los cuerpos de las mujeres que practican actividad física competitiva. Por un lado, los periodos vistos han trazado sociogenéticamente un cambio en el significado del deporte, que ha ido evolucionando desde un significado lúdico hacia uno de exigencia y de rendimiento, de modo que los cuerpos de las mujeres deportistas han sido "docilizados» a lo largo del proceso hacia nuevas técnicas corporales de rendimiento, como son los entrenamientos cada vez más exigentes y un estricto control de la dieta. Por otro lado, desde un punto de vista psicogenético y en relación con la profesionalidad conseguida, ellas han interiorizado cada vez más el sufrimiento, la necesidad de practicar actividad física regularmente - incluso en periodos de descanso en el ciclo deportivo- y el control alimentario, hasta reconocerse a sí mismas como deportistas de élite.

\section{Referencias bibliográficas}

Aalten, Anna (2007). «Listening to the dancer's body». Embodying Sociology: Retrospect, Progress and Prospect. Editado por Ch. I. Shilling. Oxford: Blackwell Publising, 109-125.

<https://doi.org/10.1111/j.1467-954x.2007.00696.x>

ATKINSON, Michael (2011). «Male Athletes and the Cult(ure) of Thinness in Sport». Deviant Behavior, 32 (3), 224-256.

<https://doi.org/10.1080/01639621003748860>

BOURDIEU, Pierre (1986). «Notas provisionales sobre la percepción social del cuerpo». En: VV. AA. Materiales de Sociología Crítica. Madrid: La Piqueta.

- (1999). Meditaciones pascalianas. Barcelona: Anagrama.

- (2000). Cosas dichas. Barcelona: Gedisa.

BRIDEL, William y RAIL, Geneviève (2007). «Sport, Sexuality, and the Production of (Resistant) Bodies: De-/Re-Constructing the Meanings of Gay Male Marathon Corporeality». Sociology of Sport Journal, 24 (2), 127-144. $<$ https://doi.org/10.1123/ssj.24.2.127>

Buñuel Heras, Ana (1994). «La construcción social del cuerpo de la mujer en el deporte». En: BAÑUElos MADERA, Carmen (coord.). Perspectivas en sociología del cuerpo. Madrid: CIS. <https://doi.org/10.2307/40183759>

Busanich, Rebecca; MCGannon, Kerry R.; SCHINKE, Robert J. (2012). «Expanding understandings of the body, food and exercise relationship in distance runners: $A$ narrative approach». Psychology of Sport and Exercise, 13 (5), 582-590. <https://doi.org/10.1016/j.psychsport.2012.03.005>

- (2014). «Comparing elite male and female distance runner's experiences of disordered eating through narrative analysis». Psychology of Sport and Exercise, 15 (6), 705-712. $<$ https://doi.org/10.1016/j.psychsport.2013.10.002>

Byrne, Susan y MCLEAN, Neil (2001). «Eating disorders in athletes: A review of the literature». Journal of Science and Medicine in Sport, 4 (2), 145-159. <https://doi.org/10.1016/S1440-2440(01)80025-6> 
CaÏs, Jordi; Folguera, Laia y Formoso, Climent (2014). Investigación Cualitativa Longitudinal. Madrid: CIS

CAmaCHO-MiÑAno, María José (2013). "Contradicciones del significado de la actividad físico-deportiva en las identidades corporales de las chicas adolescentes». En: Tortosa Martínez, Juan y Vega Ramírez, Lilyan (coords.). Mujeres, actividad fisica, deporte y ocio. Alicante: IUIEG. <https://doi.org/10.14198/fem.2013.21.02>

Cole, Cheryl L. (2000). "Body Studies in the Sociology of Sport: A Review of the Field». En: CoAckley, Jay J. y Dunning, Eric (eds.). The Handbook of Sport Studies. Londres: SAGE. <https://doi.org/10.4135/9781848608382.n28>

Cosh, Suzanne; Crabb, Shona; LeCouteur, Amanda y Kettler, Lisa (2012). "Accountability, monitoring and surveillance: Body regulation in elite sport». Journal of Health Psychology, 17 (4), 610-622. <https://doi.org/10.1177/1359105311417914>

Crossley, Nick (2001a). The Social Body: Habit, Identity and Desire. Londres: SAGE. <https://doi.org/10.4135/9781446219867>

- (2001b). "The Phenomenological Habitus and Its Construction». Theory and Society, 30 (1), 81-120. <https://doi.org/10.1023/A:1011070710987>

- (1995). «Merleau-Ponty, the Elusive Body and Carnal Sociology», Body and Society, 1 (1), 43-63. <https://doi.org/10.1177/1357034X95001001004>

- (2005). «Mapping Reflexive Body Techniques: On Body Modification and Maintenance». Body and Society, 2 (1), 1-35. <https://doi.org/10.1177/1357034X05049848>

Csordas, Thomas. J. (ed.) (1994). Embodiment and experience. Cambridge: Cambridge University Press.

Duncan, James S.; Schofield, Grant; Duncan, Elizabeth K. y Rush, Elaine C. (2008). «Risk factors for excess body fatness in New Zealand children». Asia Pacific Journal of Clinical Nutrition, 17 (1), 138-147.

ELIAS, Norbert (1987). El proceso de la civilización: Investigaciones sociogenéticas y psicogenéticas. México: Fondo de Cultura Económica. $<$ https://doi.org/10.2307/40183667>

- (1992). «Introducción». En: Elias, N. y Dunning, E. Deporte y Ocio en el Proceso de la Civilización. México: Fondo de Cultura Económica, 31-81. <https://doi.org/10.2307/40184020>

EspeITX, Elena (2005). «La construcción del cuerpo a través de la alimentación: La salud y la imagen corporal». En: DíAZ-MÉNDEZ, C. (coord.). ¿Cómo comemos?: Cambios en los comportamientos alimentarios de los españoles. 1. ${ }^{\mathrm{a}} \mathrm{ed}$. Madrid: Fundamentos, 129-153.

- (2006). «Práctica deportiva, alimentación y construcción del cuerpo». Revista de Dialectología y Tradiciones Populares, LXI (2), 79-98.

Faure, S. y García, M.C. (2002). «Danses des villes et danses d'école: Le hiphop. Procédures de l'inventivité quotidienne des "danses urbaines" confrontées aux modalités d'apprentissage lors de leur insertion en milieu scolaire». Rapport de Recherche, GRS. Université Lumière Lyon, 2.

FISCHLER, Claude (1995). El (h)omnivoro: El gusto, la cocina y el cuerpo. Barcelona: Anagrama. 
Foucault, Michel (1991). Historia de la sexualidad. Vol. 1. La voluntad de saber. México: Siglo XXI, 1977.

- (2002). Vigilar y castigar: Nacimiento de la prisión. Argentina: Siglo XXI. 1976

GARCía FERrANDO, Manuel (2006). «Veinticinco años de análisis del comportamiento de la población española (1980-2005)». RIS, 64 (44), 15-38. <https://doi.org/10.3989/ris.2006.i44.26>

Gil Gascón, Fátima y Cabeza DeOgracias, José (2012). «Pololos y medallas: La representación del deporte femenino en NO-DO (1943-1975)». Historia y Comunicación Social, 17, 195-216. <https://doi.org/10.5209/rev_hics.2012.v17.40606>

Girela Rejón, M.J. (1996). "La imagen de la mujer en la publicidad desde la perspectiva de la actividad física y el deporte». En: García FERrAndo, Manuel y Martínez Morales, Juan Ramón (coords.). Ocio y deporte en España. Valencia: Tirant Lo Blanch.

Hall, M. Ann (1996). Feminism and Sporting Bodies: Essays on Theory and Practice. USA: Human Kinetics.

Hammer, Dean y WildavsKy, Aaron (1990). «La entrevista semi-estructurada de final abierto: Aproximación a una guía operativa». Historia y Fuente Oral, 4, $23-61$.

INSTITUTO DE LA MUJER (2006). Actitudes y prácticas deportivas de las mujeres en Espana (1990-2005). Madrid: Instituto de la Mujer. MTAS, Ministerio de Trabajo y Asuntos Sociales, 258. Estudios, 92.

Jaime, Patricia C.; Duran, Ana C.; Sarti Flávia, M. y Lock, Karen (2011). «Investigating Environmental Determinants of Diet, Physical Activity, and Overweight among Adults in Sao Paulo, Brazil». Journal of Urban Health-Bulletin of The New York Academy of Medicine, 88 (3), 567-581.

<https://doi.org/10.1007/s11524-010-9537-2>

JarviE, Grant (2006). Sport, Culture and Society: An Introduction. Nueva York: Routledge. <https://doi.org/10.4324/9780203970003>

Krentz, Eva M. y Warschburger, Petra (2011). «Sports-related correlates of disordered eating in aesthetic sports». Psychology of Sport and Exercise, 12 (4), 375-382. $<$ https://doi.org/10.1016/j.psychsport.2011.03.004>

LANDE, Brian (2007). «Breathing like a soldier: Culture incarnate». Monográfico: Embodying Sociology: Retrospect, Progress and Prospect, editado por Ch. I. Shilling. Oxford: Blackwell Publising, 95-108. <https://doi.org/10.1111/j.1467-954x.2007.00695.x>

LEDER, Drew (1990). The absent body. Chicago: The University of Chicago Press.

LI, Ji y HoOKER, Neal H. (2010). "Childhood Obesity and Schools: Evidence from the National Survey of Children's Health». Journal of School Health, 80 (2), 96-103. <https://doi.org/10.1111/j.1746-1561.2009.00471.x>

Lupton, D. (1995). The Imperative of Health: Public Health and the Regulated Body. Londres: SAGE.

<https://doi.org/10.4135/9781446221976>

- (1996). Food, the Body and the Self. Londres: SAGE. <https://doi.org/10.4135/9781446221761>

- (2003). Medicine as Culture: Illness, Diseases and the Body in Western Societies. Londres: SAGE.

Manrique Arribas, Juan Carlos; Torrego Egido, Luis; López Pastor, Víctor y Monjas Aguado, Roberto (2009). «Factores que determinaron una educación 
física y deportiva de género durante el franquismo». Apunts: Educación Física y Deportes, 98 (4), 5-14.

Markula, Pirkko y Pringle, Richard (2006). Foucault, Sport and Exercise: Power, Knowledge and Transforming the Self. Nueva York: Routledge.

Mauss, Marcel (1971). Sociología y antropología. Madrid: Tecnos.

Mennell, Stephen (1996). All Manners of Food: Eating and Taste in England and France from the Middle Ages to the Present. Chicago: University of Illinois Press.

Moscoso SÁNCHEZ, David (2005). «La construcción social y cultural del liderazgo en el deporte». Apunts: Educación Física y Deportes, 79 (1), 5-12.

Moscoso SÁnchez, David; Fernández Gavira, Jesús y Rodríguez Díaz, Álvaro (2014). «De la democratización del deporte a la hegemonía de los mercados: El caso español». Movimiento: Revista da Escola de Educão Física da UFRGS, 20, 109-124.

Muñoz GonZÁlez, Beatriz; Rivero JiméneZ, Borja y Fondón LudeñA, Ana (2013). «Feminidad hegemónica y limitación a la práctica deportiva». En: TORTOSA MARTÍNEZ, Juan y VEGA RAMírEZ, Lilyan (coords.). Mujeres, actividad fisica, deporte y ocio. Alicante: IUIEG. $<$ https://doi.org/10.14198/fem.2013.21.03>

Navalpotro, Lourdes; Regidor, Enrique; Ortega, Paloma; Martínez, David; VillanueVa, Rosa y Astasio, Paloma (2012). "Area-based socioeconomic environment, obesity risk behaviours, area facilities and childhood overweight and obesity: Socioeconomic environment and childhood overweight». Preventive Medicine, 55 (2), 102-107. <https://doi.org/10.1016/j.ypmed.2012.05.012>

Petersen, A. y Lupton, D. (2000). The New Public Health: Health and the Self in the Age of Risk. Londres: SAGE. <https://doi.org/10.4135/9781446217429>

Puig Barata, Núria y Soler Prat, Susanna (2004). "Mujer y deporte en España: Estado de la cuestión y propuesta interpretativa». Apunts: Educación Física y Deportes, 76, 71-78.

Pujadas i Martí, Xavier; Garai Ibáñez de Elejalde, Beatriz; Gimeno Marco, Fernando; Llopis Goig, Ramon; Ramírez MaCías, Gonzalo y PARrilla FernándeZ, José Manuel (2012). «Mujeres y deporte durante el franquismo (1939-1975): Estudio piloto sobre la memoria oral de las deportistas». Materiales para la Historia del Deporte, 10, 37-53.

- (2016). «Sports, morality and body: The voices of sportswomen under Franco's dictatorship». International Review for the Sociology of Sport, 51 (6), 679-698. <https://doi.org/10.1177/1012690214551182>

SHILling, Chris (2003). The Body and Social Theory. Londres: SAGE, 1993. $<$ https://doi.org/10.4135/9781446215470>

- (2005). The Body in Culture, Technology and Society. Londres: SAGE. <https://doi.org/10.4135/9781446220818>

Smith Maguire, Jennifer (2010). «Body lessons: Publishing and the cultural production of the fitness consumer». En: Consumption. Vol. II. Acquisition. Londres: SAGE, 345-360.

Theberge, Nancy (2012). «Gender and Sport». En: CoAckley, Jay J. y Dunning, Eric (eds.). The Handbook of Sport Studies. Londres: SAGE.

Turner, Bryan S. (1984). The Body and Society: Explorations in Social Theory. Londres: SAGE, 2008. <https://doi.org/10.4135/9781446214329> 
Vigarello, Georges (2006). Lo sano y lo malsano: Historia de las prácticas de la salud desde la Edad Media hasta nuestros días. Madrid: Abada.

WACQUANT, Loïc (2004). Body \& Soul: Notebooks of an apprentice boxer. Oxford: Oxford University Press.

- (2016). "A concise genealogy and anatomy of habitus». The sociological Review, 64, (1), 64-72. https://doi.org/10.1111/1467-954X.12356>

Waldron, Jennifer J. y KranE, Vikki (2005). «Whatever it Takes: Health Compromising Behaviors in Female Athletes». Quest, 57 (3), 315-329. <https://doi.org/10.1080/00336297.2005.10491860>

Williamson, Donald A.; Netemeyer, Richard G.; Jackman, Lori P.; Anderson, Drew A.; FunsCH, Cheryl L. y RABALAIS, Jodie Y. (1995). «Structural equation modeling of risk factors for the development of eating disorder symptoms in female athletes». International Journal of Eating Disorders, 17 (4), 387-393. <https://doi.org/10.1002/1098-108X(199505)17:4<387::AID-EAT2260170411> 3.0. $\mathrm{CO} ; 2-\mathrm{M}>$

\section{Anexo I}

Tabla 1. Composición de la muestra (entrevistas realizadas)

\begin{tabular}{ccclll}
\hline & Años que & Año de & Clave de & & \\
Período & comprende & nacimiento la entrevista & Deporte principal & Grado de competición \\
\hline I & $1940-1959$ & 1934 & Entr.PF/1 & Balonmano & Competición nacional. \\
& & 1930 & Entr.PF/2 & Baloncesto & Competición nacional e internacional. \\
& & 1927 & Entr.PF/3 & Natación & Competición nacional. \\
\hline II & \multirow{2}{*}{$1960-1979$} & 1948 & Entr.TF/1 & Voleibol & Competición nacional e internacional. \\
& & 1945 & Entr.TF/2 & Piragüismo y voleibol & Competición nacional. \\
& & 1944 & Entr.TFN/3 & Tenis & Competición nacional. \\
\hline III & \multirow{2}{*}{$1980-1999$} & 1960 & Entr.80-90/1 & Gimnasia & Competición nacional. \\
& & 1969 & Entr.80-90/2 & Atletismo & Competición nacional e internacional. \\
& & 1958 & Entr.80-90/3 & Voleibol & Competición nacional. \\
\hline IV & \multirow{2}{*}{ 2000-actual } & 1983 & Entr.90-act/1 & Piragüismo & Competición nacional e internacional. \\
& & 1990 & Entr.90-act/2 & Ciclismo & Competición nacional. \\
& & 1982 & Entr.90-act/3 & Fútbol & Competición nacional e internacional. \\
\hline
\end{tabular}

Fuente: elaboración propia. 